\section{Persistent and recurrent disease in patients with papillary thyroid carcinoma with clinically apparent (cN1), but not extensive, lymph node involvement and without other factors for poor prognosis}

Mariana de Souza Furtado ${ }^{1,2}$, Pedro Weslley Rosario ${ }^{1,3}$, Maria Regina Calsolari ${ }^{3}$

\begin{abstract}
Objective: Lymph node metastases (LNM) are frequent in patients with papillary thyroid cancer (PTC). The risk of persistent disease (PD) and tumor recurrence (TR) is increased when factors for poor prognosis other than LNM exist, when LNM are numerous, large, detected by preoperative ultrasonography (US), or exhibit extranodal extension. This study evaluated the risk of PD and TR in patients with LNM not exhibiting these characteristics. Subjects and methods: Eighty-six patients with 5 or fewer LNM detected during intraoperative inspection, but not by preoperative US, who had no other factors for poor prognosis [tumors $>4 \mathrm{~cm}$, extensive extrathyroid invasion, vascular invasion, aggressive histological subtype, distant metastases, incomplete tumor resection], were studied. All patients underwent total thyroidectomy followed by radioiodine ablation. PD was defined as metastases on initial post-therapy whole-body scans (RxWBS) or detected by imaging methods up to 12 months after ablation. TR was defined as structural disease diagnosed more than one year after ablation in patients without PD. Results: PD was diagnosed in $3 / 86$ patients (3.5\%). TR was observed in $2 / 83$ patients $(2.5 \%)$ after 62 months of follow-up. There was no case of death due to the disease. A correlation was observed between pre-ablation Tg and PD or TR [1/48 $(2 \%)$ with Tg $\leq 2 \mathrm{ng} / \mathrm{mL}$ versus $2 / 22(9 \%)$ with $\mathrm{Tg}>2 \leq 10 \mathrm{ng} / \mathrm{mL}$ versus $2 / 7(28.5 \%)$ with $\mathrm{Tg} \geq 10 \mathrm{ng} / \mathrm{ml})]$. It is noteworthy that 38 patients had up to 3 positive LN and pre-ablation Tg $\leq 2 \mathrm{ng} / \mathrm{ml}$, and none of them had PD orTR. Conclusions: The frequency of PD and TR was low in patients with PTC with 5 or fewer LNM and without other factors for poor prognosis. Low postoperative stimulated Tg was predictive of the absence of PD and TR in these patients. Arch Endocrinol Metab. 2015;59(4):285-91
\end{abstract}

Keywords

Thyroid cancer; lymph node metastases; persistent or recurrent disease; preoperative ultrasonography
1 Programa de Pós-graduação, Santa Casa de Belo Horizonte, Belo Horizonte, MG, Brazil ${ }^{2} \mathrm{IMES} /$ Famevaço, Faculdade de Medicina do Vale do Aço, Ipatinga, MG, Brazil ${ }^{3}$ Serviço de Endocrinologia, Santa Casa de Belo Horizonte, Belo Horizonte, MG, Brazil

Correspondence to: Pedro W. Rosario Instituto de Ensino e Pesquisa, Santa Casa de Belo Horizonte Rua Domingos Vieira, 590 30150-240 - Belo Horizonte, MG, Brazil

pedrowsrosario@gmail.com

Received on Apr/6/2015 Accepted on May/11/2015

DOI: 10.1590/2359-3997000000081

\section{INTRODUCTION}

L ymph node metastases (LNM) are frequent in patients with papillary thyroid cancer (PTC). Although the impact on the prognosis is questionable, the presence of clinically apparent LNM [CNl, defined as LNM identified by preoperative physical examination or ultrasonography (US), or intraoperative inspection by the surgeon] excludes the patient from the group of low recurrence risk (1-6) and frequently indicates a more aggressive initial approach (1-8).

When factors for poor prognosis other than LNM exist, such as tumor size $>4 \mathrm{~cm}$, aggressive histological subtype, extensive extrathyroid invasion (pT4), vas- cular invasion and distant metastases (Ml), or when tumor resection was incomplete, there is consensual indication of ablation/therapy with ${ }^{131} \mathrm{I}$, TSH suppression, and external radiotherapy, occasionally, after total thyroidectomy. Furthermore, the risk of persistent disease [defined as metastases on initial posttherapy whole body scanning (RxWBS) or detected by the imaging methods until one year after ablation] and tumor recurrence (defined as strutural disease diagnosed more than one year after ablation) is significantly increased when LNM are detected by preoperative US (9-14), in the presence of numerous [ $>5$ positive LN $(11,15-18)]$ and large LNM $[\geq 3 \mathrm{~cm}(11,16,19)]$, or in the presence of extranodal tumor extension (15,16,18-21). 
The most relevant discussion is to know the risk of persistent disease and tumor recurrence in the patients with LNM not exhibiting the characteristics described above (22) and in the absence of other factors for poor prognosis. The present study was conducted to answer this question. The criterion used for the definition of LN status (preoperative US and intraoperative inspection by the surgeon) agrees with current guidelines since there is no clear indication for elective $\mathrm{LN}$ dissection in patients with tumors $\leq 4 \mathrm{~cm}$ and without apparent extrathyroid invasion $(1-7,23)$.

\section{SUBJECTS AND METHODS}

The data of patients with diagnosis of PTC treated at our institution from 2004 to 2012 were reviewed. The limit of 2012 was established to obtain a minimum follow-up of 24 months. The study was approved by the Research Ethics Committee of our Institution.

\section{Patients}

Patients with suspicious or diagnostic cytology of PTC were routinely submitted to neck US before surgery. For this study, only patients with negative preoperative US for LNM were selected. All patients underwent to- tal thyroidectomy. During intraoperative inspection by the surgeon, patients with a suspicion of LNM in the central neck compartment were submitted to bilateral dissection of this compartment combined with exploration of the lateral compartments. Elective LN dissection was not performed. Patients with tumors $>4 \mathrm{~cm}$, extensive extrathyroid invasion (pT4), vascular invasion, aggressive histological subtype (tall-cell, columnar-cell, diffuse follicular variant), distant metastases (clinical examination or simple chest $\mathrm{x}$-ray), or incomplete tumor resection were excluded. Additionally, patients with $>5$ positive LN or LNM exhibiting macroscopic extranodal tumor invasion $(16,19,21)$ also were excluded. Finally, patients with 5 or fewer positive LN detected during intraoperative inspection, but not by preoperative US, and in the absence of macroscopic extranodal extension; without other factors for poor prognosis were studied.

About 3 months after surgery, before ablation, a new US scan was obtained to exclude patients with incomplete tumor resection (Figure 1).

\section{Ablation with ${ }^{131}$ |}

Approximately 4 months after thyroidectomy, all patients were submitted to ablation with ${ }^{131} \mathrm{I}$ [1.1-5.5 GBq (30$150 \mathrm{mCi})$ ] after withdrawal of levothyroxine (L-T4) for

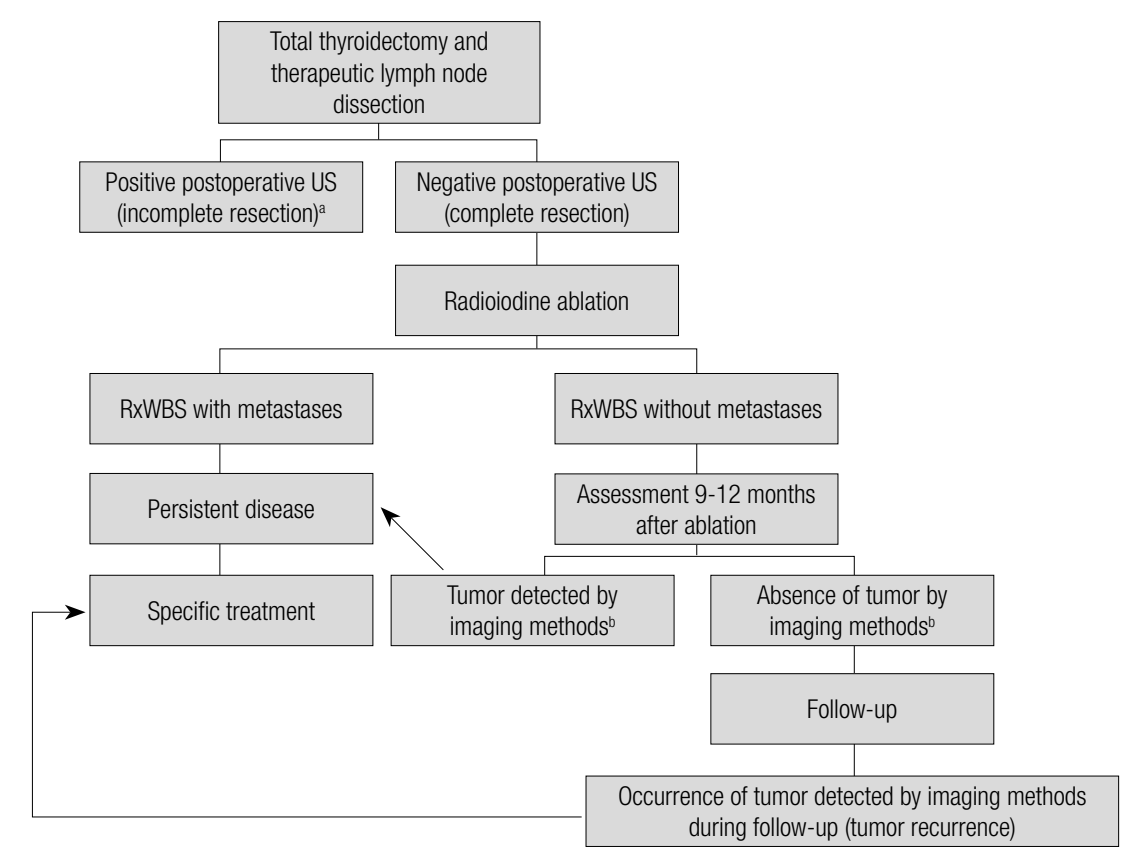

Figure 1. Sequence of patient management and definitions used in this study. US: ultrasonography; RxWBS: post-therapy whole-body scanning. ${ }^{\text {a }}$ These patients were excluded. ${ }^{\mathrm{b}}$ Imaging methods: US in all patients; chest and mediastinal CT if Tg $>1 \mathrm{ng} / \mathrm{mL}$; MIBI scan and FDG-PET/CT if basal Tg $>1 \mathrm{ng} / \mathrm{mL}$ or $\mathrm{Tg}>5 \mathrm{ng} / \mathrm{mL}$ after rhTSH or $>10 \mathrm{ng} / \mathrm{mL}$ after levothyroxine withdrawal, or $\mathrm{Tg}>1 \mathrm{ng} / \mathrm{mL}$ in the presence of anti-Tg antibodies. 
4 weeks and prior administration of a low-iodine diet for 10-14 days. Thyroglobulin (Tg) and anti-thyroglobulin antibodies $(\mathrm{TgAb})$ were measured immediately before the administration of ${ }^{131} \mathrm{I}$. Anterior and posterior wholebody images were obtained 7 days after ablation with ${ }^{131} \mathrm{I}$ [post-therapy whole-body scanning (RxWBS)].

\section{Assessment 9-12 months after ablation}

Patients showing no ectopic uptake on RxWBS were evaluated 9 to 12 months after ablation by measurement of Tg on L-T4 (Tg/T4) and TgAb and neck US. Other imaging methods [chest computed tomography (CT), whole-body scanning with ${ }^{99 \mathrm{~m} T c-s e s t a m i b i, ~ f l u o-}$ rodeoxyglucose-positron emission tomography (FDG$\mathrm{PET}) / \mathrm{CT}$ )] were performed on patients with negative US and $\mathrm{Tg} / \mathrm{T} 4>\mathrm{lng} / \mathrm{ml}$. Stimulated Tg [after L-T4 withdrawal or recombinant human TSH (rhTSH)] was obtained for patients with $\mathrm{Tg} / \mathrm{T} 4<\mathrm{lng} / \mathrm{ml}$ and negative US. Patients with stimulated $\mathrm{Tg}>1 \mathrm{ng} / \mathrm{mL}$ were submitted to chest CT (24). Additionally, ${ }^{99 \mathrm{~m} T c}$ sestamibi scans and FDG-PET/CT were performed on patients with $\mathrm{Tg}>10 \mathrm{ng} / \mathrm{mL}$ after L-T4 withdrawal or $>5 \mathrm{ng} / \mathrm{ml}$ after $\operatorname{rhTSH}(24,25)$, or stimulated $\mathrm{Tg}>\mathrm{l}$ $\mathrm{ng} / \mathrm{mL}$ in the presence of $\operatorname{TgAb}(26)$.

\section{Persistent disease}

Persistent disease was defined as ectopic (metastatic) uptake on initial posttherapy whole body scanning ( $\mathrm{Rx}-$ WBS) or metastases detected by the imaging methods 9-12 months after ablation (Figure 1).

\section{Late follow-up}

Patients without metastases detected on initial RxWBS or by the imaging methods $9-12$ months after ablation were followed up by annual measurement of $\mathrm{Tg} / \mathrm{T} 4$ and $\mathrm{TgAb}$ and neck US. Patients with initial $\mathrm{Tg} / \mathrm{T} 4$ levels $<\mathrm{lng} / \mathrm{ml}$, but with stimulated $\mathrm{Tg}>\mathrm{l} \mathrm{ng} / \mathrm{mL}$, were submitted to new $\mathrm{Tg}$ stimulation at an interval of 2 years (27). Imaging methods other than US (chest CT, ${ }^{99 \mathrm{~m} T c-s e s t a m i b i}$ scans, FDG-PET/CT and RxWBS after an empirical activity of $3.7 \mathrm{GBq}{ }^{131} \mathrm{I}$ ) were performed when: (i) $\mathrm{Tg} / \mathrm{T} 4<\mathrm{lng} / \mathrm{mL}$ converted to levels $>1$ $\mathrm{ng} / \mathrm{mL}$, (ii) there was an increase $>50 \%(25,27)$ in $\mathrm{Tg}$ ( $\mathrm{Tg} / \mathrm{T} 4$ or stimulated $\mathrm{Tg}$ ) when $\mathrm{Tg}$ was already $>\mathrm{lng} / \mathrm{mL}$, (iii) negative $\operatorname{TgAb}$ became positive, or (iv) there was an increase in already positive $\mathrm{TgAb}$ titers. The patients were maintained on a dose of L-T4 sufficient to obtain serum TSH $\leq 0.5 \mathrm{mIU} / 1$. The time of follow-up ranged from 30 to 102 months (median 62 months).

\section{Tumor recurrence}

Tumor recurrence was defined as structural disease diagnosed more than one year after ablation in patients without persistent disease (Figure 1).

The diagnosis of tumor in lesions detected by the imaging methods was made by cytology or histology, and/or based on unequivocal ectopic uptake (excluding false-positive results) on RxWBS or FDG$\mathrm{PET} / \mathrm{CT}$.

\section{Methods}

Until 2006, $\mathrm{Tg}$ was measured with a radioimmunometric assay (ELSA-hTG; CIS Bio International, France) with a functional sensitivity of $1 \mathrm{ng} / \mathrm{ml}$. After 2006, $\mathrm{Tg}$ was measured with a chemiluminescent assay (Access Thyroglobulin Assay, Beckman Coulter, Fullerton, $\mathrm{CA}$ ) with a functional sensitivity of $0.1 \mathrm{ng} / \mathrm{mL}$. TgAb were measured with a chemiluminescent assay [Immulite 2000, Diagnostic Products Corporation, Los Angeles, CA (reference value of up to $40 \mathrm{IU} / \mathrm{ml}$ ) or ARCHITET Anti-Tg, Abbott Laboratories, IL (reference value of up to $4.11 \mathrm{IU} / \mathrm{mL})]$.

US was performed with a linear multifrequency transducer for morphological analysis (B-mode) and for Doppler evaluation. US was performed by a radiologist with experience in thyroid and neck US. US was defined as negative when it did not detect suspicious lesions $(28,29)$ or, in the presence of these lesions, when cytology and $\mathrm{Tg}$ measurement in the needle washout obtained by US-guided fine-needle aspiration were negative. Chest CT was performed by taking $5-\mathrm{mm}$ sequential sections. ${ }^{99 \mathrm{~m}} \mathrm{Tc}$-sestamibi scans were performed under L-T4 therapy using a tracer dose of 720-925 MBq. FDG-PET/CT was carried out after stimulation with rhTSH.

\section{Statistical analysis}

The $\chi^{2}$ test was used to detect differences in the proportion of cases. Multivariate Cox regression models were used to assess the independent effect of different variables on the risk for persistent disease or tumor recurrence. A p value of less than 0.05 was considered to be significant.

\section{RESULTS}

\section{Patients}

The characteristics of the patients are shown in table 1 . 
Table 1. Characteristics of the 86 patients studied

\begin{tabular}{lc}
\hline Patients & $67(78 \%)$ \\
\hline Women & $19(22 \%)$ \\
Men & 10 to 78 (median 46$)$ \\
Age (years) & \\
Tumor & 3.05 \\
Size, mean (cm) & $29(33.7 \%)$ \\
$\leq 2 \mathrm{~cm}$ & $57(66.3 \%)$ \\
$>2 \mathrm{~cm}$ and $\leq 4 \mathrm{~cm}$ & $34(39.5 \%)$ \\
Multicentricity & $40(46.5 \%)$ \\
Extrathyroid invasion (pT3) & $4(4.6 \%)$ \\
T1a & $10(11.6 \%)$ \\
T1b & $32(37.2 \%)$ \\
T2 & $40(46.5 \%)$ \\
T3 & \\
Lymph node metastases & Central and lateral: $10(12 \%)$ \\
Location & Only central: $76(88 \%)$ \\
& $1: 10(11.6 \%)$ \\
\hline Number of positive lymph nodes & $2: 27(31.4 \%)$ \\
& $3: 27(31.4 \%)$ \\
& $4: 12(14 \%)$ \\
& $5: 10(11.6 \%)$ \\
\hline
\end{tabular}

\section{Ablation with ${ }^{131}$}

The frequency of ectopic (metastatic) uptake on RxWBS is shown in table 2 . Table 2 also shows the correlation between $\operatorname{TgAb}$ and $\mathrm{Tg}$ obtained immediately before $\mathrm{ab}$ lation and the presence of metastases on RxWBS. In patients without $\mathrm{TgAb}$, median $\mathrm{Tg}$ was $3.57 \mathrm{ng} / \mathrm{dL}$.

\section{Initial assessment after ablation}

The results of assessment 9-12 months after ablation obtained for patients without metastases on initial

Table 2. Correlation between $\operatorname{TgAb}$ and $\mathrm{Tg}$ obtained immediately before ablation and the presence of ectopic (metastatic) uptake on RxWBS

\begin{tabular}{lcc}
\hline & & Positive RxWBS \\
\hline All patients & 86 & $2 / 86(2.3 \%)$ \\
Positive TgAb & 9 & $0 / 9$ \\
Negative $\mathrm{TgAb}$ & & \\
$\mathrm{Tg} \leq 2 \mathrm{ng} / \mathrm{mL}$ & 48 & $0 / 48$ \\
$\mathrm{Tg}>2 \mathrm{ng} / \mathrm{mL}$ and $\leq 10 \mathrm{ng} / \mathrm{mL}$ & 22 & $1^{\mathrm{a}} / 22(4.5 \%)$ \\
$\mathrm{Tg}>10 \mathrm{ng} / \mathrm{mL}$ & 7 & $1^{\mathrm{b} / 7}(14.3 \%)$ \\
\hline
\end{tabular}

aEctopic cervical uptake (lymph node metastases).

b Pulmonary uptake.
RxWBS is shown in table 3 . In this assessment, three patients had suspicious LN on US, but cytology was negative and $\mathrm{Tg}$ in the needle washout was $<\mathrm{lng} / \mathrm{mL}$.

Persistent disease was detected in $3 / 86$ patients $(3.5 \%)$.

Table 3. Result of assessment 9-12 months after ablation obtained for patients without metastases on initial RxWBS

\begin{tabular}{lc}
\hline & $\mathbf{n}=\mathbf{8 4}$ \\
\hline Positive $\mathrm{TgAb}$ and stimulated $\mathrm{Tg}<1 \mathrm{ng} / \mathrm{mL}$ & $5(6 \%)$ \\
Negative $\mathrm{TgAb}$ & \\
Stimulated $\mathrm{Tg} \leq 1 \mathrm{ng} / \mathrm{mL}$ & $70(83.3 \%)$ \\
Stimulated $\mathrm{Tg}>1 \mathrm{ng} / \mathrm{mL}$ and $\leq 5$ or $10 \mathrm{ng} / \mathrm{mL}^{\mathrm{b}}$ & $8(9.5 \%)$ \\
Stimulated $\mathrm{Tg}>5$ or $10 \mathrm{ng} / \mathrm{mL}^{\mathrm{b}}$ & $1^{\mathrm{a}}(1.2 \%)$ \\
\hline
\end{tabular}

a This patient had apparent disease on CT and FDG-PET/CT in lymph nodes.

${ }^{b}$ Cut-off of $5 \mathrm{ng} / \mathrm{mL}$ after rhTSH and of $10 \mathrm{ng} / \mathrm{mL}$ after L-T4 withdrawal.

\section{Late follow-up}

Among patients without apparent disease until the first year after ablation, tumor recurrence was diagnosed in 2/83 (2.4\%) patients (both with cervical metastases: one with positive cytology and the other with nondiagnostic cytology, but $\mathrm{Tg}$ in the needle washout > $400 \mathrm{ng} / \mathrm{mL}$ ). Three patients exhibited suspicious LN on US during follow-up, but cytology was negative and $\mathrm{Tg}$ in the needle washout was $<\mathrm{lng} / \mathrm{mL}$.

\section{Evolution of patients with persistent disease or tumor recurrence}

In the last assessment, after they had undergone new surgery (LN dissection) and/or had been treated with radioiodine and maintained under TSH suppression, three patients had achieved complete remission, structural disease persisted in one patient, and other patient had elevated $\mathrm{Tg}$ in the absence of apparent disease. There was no case of death due to the disease.

\section{Factors predicting persistent or recurrent tumors}

Sex, age ( $<45$ versus $>45$ years), location of LNM (central compartment only versus central and lateral compartments), extrathyroid invasion (pT3), tumor size $(\leq 2 \mathrm{~cm}$ versus $2-4 \mathrm{~cm})$ or tumor multicentricity was not predictive of persistent or recurrent tumor. A correlation was observed between pre-ablation $\mathrm{Tg}$ and persistent or recurrent tumor $[1 / 48(2 \%)$ with $\mathrm{Tg} \leq 2$ $\mathrm{ng} / \mathrm{ml}$ versus $2 / 22(9 \%)$ with $\mathrm{Tg}>2 \leq 10 \mathrm{ng} / \mathrm{ml}$ versus $2 / 7(28.5 \%)$ with $\mathrm{Tg} \geq 10 \mathrm{ng} / \mathrm{mL})]$. Three of 64 
patients $(4.6 \%)$ with up to 3 positive $\mathrm{LN}$ versus $2 / 22$ (9\%) with 4 or 5 positive LN had persistent or recurrent tumor, but the difference was not significant. It is noteworthy that 38 patients of group $\mathrm{cNl}$ had up to 3 positive $\mathrm{LN}$ and pre-ablation $\mathrm{Tg} \leq 2 \mathrm{ng} / \mathrm{mL}$ in the absence of $\mathrm{TgAb}$, and none of them had persistente disease or tumor recurrence.

\section{DISCUSSION}

It does not seem adequate to classify all patients with LNM and without distant metastases (NIM0) into a single group (30) since their evolution is highly heterogenous. These patients (N1M0) have a poorer prognosis if the primary tumor measures more than $4 \mathrm{~cm}$ $(11,15,19,31)$ or aggressive histological subtype (32), and if there is extensive extrathyroid invasion (pT4) $(11,17,19,33)$ or vascular invasion $(18,33)$. With respect to the characteristics of LN involvement, metastases detected by preoperative US (9-14), the presence of more than 5 positive $\mathrm{LN}(11,15-18)$, metastases $\geq 3 \mathrm{~cm}$ $(11,16,19)$, and extranodal extension $(15,16,18-21)$ are also associated with a poor prognosis $(4,5,7,22)$. In these cases, there is little controversy about the need for a more aggressive initial approach. Therefore, the present study was designed to define the rate of persistent disease and tumor recurrence in patients without other factors for poor prognosis, who presented nonextensive LN involvement (22).

US is an accessible, noninvasive method consensually recommended before thyroidectomy. When preoperative US is negative, LNM, if present, are invariably $<3 \mathrm{~cm}$ and the vast majority is $<1-1.5 \mathrm{~cm}(11,34-37)$. For this reason, although the size of the LN and metastatic foci was not available for our patients, the fact that US was negative ensures the absence of LNM > $3 \mathrm{~cm}$ and makes LNM $>1.5 \mathrm{~cm}$ highly unlikely. Although defined as an exclusion criterion of the present study, macroscopic extranodal invasion is uncommon in the case of small LNM $(16,20,38)$ and not present in large numbers $(15,16,38)$. In fact, extranodal invasion was observed in only $7 / 466$ patients with $\mathrm{LNM}<3 \mathrm{~cm}$ and up to 5 positive $\mathrm{LN}$ in a previous series (16) and in only $1 / 87$ patients with negative US and up to 5 positive LN in the present study (data not shown). A possible poor prognosis related to the location of LNM in the lateral compartments $(\mathrm{Nlb})$ also seems to be minimized when US is negative (9-12). Finally, the efficacy of initial LN dissection, based on the persistence or not of LNM after surgery (39), is an important prognostic factor. In this respect, the fact that we included only patients with apparently complete tumor resection and postoperative US negative for LNM may have contributed to the result found.

Thus, persitent disease and tumor recurrence were found in only $3.5 \%$ and $2.5 \%$ (respectively) of patients without other factors for poor prognosis, with 5 or fewer positive $\mathrm{LN}$ detected during intraoperative inspection, but not by preoperative US, during a median follow-up of 5 years, a period during which $80 \%$ of recurrence are usually detected (40). Similar results have been reported by Ricarte-Filho and cols. in patients younger than 45 years (17) and by Leboulleux and cols. (15). It should also be noted that the patients had LNM that were detected during intraoperative inspection $(\mathrm{cNl})$, and it could be possible that the rate of persistent disease and tumor recurrence are even lower among patients with LNM detected only during elective neck dissection ( $\mathrm{cN} 0 \mathrm{pNl}$ ).

In low-risk patients without LNM (cN0), postoperative $\mathrm{Tg}<\mathrm{lng} / \mathrm{mL}$ has shown an excellent negative predictive value (NPV) for PRD (4l-45), even when they are not submitted to ablation with ${ }^{131} \mathrm{I}(41,44,45)$. In the present study, also in the subgroup of patients with LNM ( $\mathrm{cNl}$ ), postoperative stimulated Tg combined with neck US had an excellent NPV for persistent disease and tumor recurrence. Previous series involving a smaller number of patients with LNM also showed the absence of persistent disease on RxWBS in patients with low postoperative $\operatorname{Tg}$ (46-49). However, there are studies reporting apparently different results. Nascimento and cols. evaluated 102 patients with stage Tl-3Nl disease whose US showed no abnormalities and stimulated $\mathrm{Tg}$ was $<1 \mathrm{ng} / \mathrm{ml}$ after thyroidectomy (43). The authors showed unequivocal ectopic uptake on RxWBS in six patients and suspicious uptake in one but, different from our sample, five of these patients had more than 5 positive LN (43). Robenshtok and cols. studied 84 patients with stage Tl-3Nl disease and postoperative $\mathrm{Tg}<0.6 \mathrm{ng} / \mathrm{mL}$ and found ectopic uptake on RxWBS (SPECT/CT) in eight; however, in contrast to the cases studied here, seven of these patients had $>5$ positive $\mathrm{LN}$ or $\mathrm{LNM}>3 \mathrm{~cm}$ or vascular invasion or the aggressive histological subtype (50). Furthermore, in the latter study, $\mathrm{Tg}$ was not obtained under TSH stimulation and postoperative US was not performed (50). Finally, Lepoutre-Loussey and cols. found ectopic uptake on RxWBS in 28/171 patients 
with stage $\mathrm{Nl}$ disease, $\mathrm{Tg}$-ablation $<1 \mathrm{ng} / \mathrm{mL}$, and negative postoperative US (39). However, the authors did not report how many of these patients had tumors $>4 \mathrm{~cm}$, aggressive histology, and extensive extrathyroid invasion, nor did they describe the characteristics of the LNM (size, number, extranodal extension). Furthermore, patients with TgAb were not excluded. Nevertheless, more studies are needed to determine the NPV of postoperative $\mathrm{Tg}$ in the absence of $\mathrm{TgAb}$, especially under TSH stimulation and combined with US, in patients with LNM (Nl) without other factors for poor prognosis and non-extensive LN involvement. This information is very important since the demonstration of an excellent NPV of low postoperative Tg would be an argument favoring the adoption of this criterion in order to also exempt patients with LNM and with the characteristics described above from ablation.

We conclude that persistent disease and tumor recurrence were low in patients with 5 or fewer positive LN detected during intraoperative inspection, but not by preoperative US; without other factors for poor prognosis [tumor $\leq 4 \mathrm{~cm}$ of non-aggressive histological subtype, without extensive extrathyroid invasion (pT4) or vascular invasion and known distant metastases (Ml), and apparently complete tumor resection]. Low postoperative stimulated $\mathrm{Tg}$ was predictive of the $\mathrm{ab}$ sence of persitent or recurrent tumor in these patients.

Disclosure: no potential conflict of interest relevant to this article was reported.

\section{REFERENCES}

1. Pacini $F$, Schlumberger $M$, Dralle $H$, Elisei $R$, Smit JW, Wiersinga W; European Thyroid Cancer Taskforce. European consensus for the management of patients with differentiated thyroid carcinoma of the follicular epithelium. Eur J Endocrinol. 2006;154(6):787-803.

2. American Thyroid Association (ATA) Guidelines Taskforce on Thyroid Nodules and Differentiated Thyroid Cancer; Cooper DS, Doherty GM, Haugen BR, Kloos RT, Lee SL, Mandel SJ, et al. Revised American Thyroid Association management guidelines for patients with thyroid nodules and differentiated thyroid cancer. Thyroid. 2009;19(11):1167-214.

3. Pitoia F, Ward L, Wohllk N, Friguglietti C, Tomimori E, Gauna A, et al. Recommendations of the Latin American Thyroid Society on diagnosis and management of differentiated thyroid cancer. Arq Bras Endocrinol Metabol. 2009;53(7):884-7.

4. Pacini F, Castagna MG, Brilli L, Pentheroudakis G; ESMO Guidelines Working Group. Thyroid cancer: ESMO Clinical Practice Guidelines for diagnosis, treatment and follow-up. Ann Oncol. 2012;23 Suppl 7:110-9.

5. Rosário PW, Ward LS, Carvalho GA, Graf H, Maciel RM, Maciel LM, et al. Thyroid nodules and differentiated thyroid cancer: update on the Brazilian consensus. Arq Bras Endocrinol Metabol. 2013;57(4):240-64.
6. Perros P, Boelaert K, Colley S, Evans C, Evans RM, Gerrard Ba $G$, et al. Guidelines for the management of thyroid cancer. Clin Endocrinol (Oxf). 2014;81(Suppl 1):1-122.

7. NCCN Clinical Practice Guidelines in Oncology: Thyroid Carcinoma version 2.2014.

8. UpToDate - Radioiodine treatment of differentiated thyroid cancer. Available from: <www.uptodate.com>. Accessed on: Jul 15, 2014.

9. Ito $Y$, Tomoda $C$, Uruno T, Takamura $Y$, Miya A, Kobayashi $K$, et al. Preoperative ultrasonographic examination for lymph node metastasis: usefulness when designing lymph node dissection for papillary microcarcinoma of the thyroid. World J Surg. 2004;28(5):498-501.

10. Ito $Y$, Tomoda C, Uruno T, Takamura $Y$, Miya A, Kobayashi K, et al. Ultrasonographically and anatomopathologically detectable node metastases in the lateral compartment as indicators of worse relapse-free survival in patients with papillary thyroid carcinoma. World J Surg. 2005;29(7):917-20.

11. Sugitani I, Fujimoto Y, Yamada K, Yamamoto N. Prospective outcomes of selective lymph node dissection for papillary thyroid carcinoma based on preoperative ultrasonography. World J Surg. 2008;32(11):2494-502.

12. Moreno MA, Agarwal G, de Luna R, Siegel ER, Sherman SI, Edeiken-Monroe BS, et al. Preoperative lateral neck ultrasonography as a long-term outcome predictor in papillary thyroid cancer. Arch Otolaryngol Head Neck Surg. 2011;137(2):157-62.

13. Moreno MA, Edeiken-Monroe BS, Siegel ER, Sherman SI, Clayman GL. In papillary thyroid cancer, preoperative central neck ultrasound detects only macroscopic surgical disease, but negative findings predict excellent long-term regional control and survival. Thyroid. 2012;22(4):347-55.

14. Poehls JL, Chen H, Sippel RS. Preoperative ultrasonography findings predict the need for repeated surgery in papillary thyroid cancer. Endocr Pract. 2012;18(3):403-9.

15. Leboulleux S, Rubino C, Baudin E, Caillou B, Hartl DM, Bidart JM, et al. Prognostic factors for persistent or recurrent disease of papillary thyroid carcinoma with neck lymph node metastases and/or tumor extension beyond the thyroid capsule at initial diagnosis. J Clin Endocrinol Metab. 2005;90(10):5723-9.

16. Ito $Y$, Fukushima $M$, Tomoda $C$, Inoue $H$, Kihara $M$, Higashiyama $\mathrm{T}$, et al. Prognosis of patients with papillary thyroid carcinoma having clinically apparent metastasis to the lateral compartment. Endocr J. 2009;56(6):759-66.

17. Ricarte-Filho J, Ganly I, Rivera M, Katabi N, Fu W, Shaha A, et al. Papillary thyroid carcinomas with cervical lymph node metastases can be stratified into clinically relevant prognostic categories using oncogenic BRAF, the number of nodal metastases, and extra-nodal extension. Thyroid. 2012;22(6):575-84.

18. Wu MH, Shen WT, Gosnell J, Duh OY. Prognostic significance of extranodal extension of regional lymph node metastasis in papillary thyroid cancer. Head Neck. 2014.

19. ItoY, Kudo T, TakamuraY, Kobayashi K, Miya A, Miyauchi A. Lymph node recurrence in patients with $\mathrm{N} 1 \mathrm{~b}$ papillary thyroid carcinoma who underwent unilateral therapeutic modified radical neck dissection. World J Surg. 2012;36(3):593-7.

20. Yamashita H, Noguchi S, Murakami N, Toda M, Uchino S, Watanabe $S$, et al. Extracapsular invasion of lymph node metastasis. A good indicator of disease recurrence and poor prognosis in patients with thyroid microcarcinoma. Cancer. 1999;86(5):842-9.

21. Ito $Y$, Hirokawa M, Jikuzono T, Higashiyama T, Takamura Y, Miya $A$, et al. Extranodal tumor extension to adjacent organs predicts a worse cause-specific survival in patients with papillary thyroid carcinoma. World J Surg. 2007;31(6):1194-201.

22. Randolph GW, Duh QY, Heller KS, LiVolsi VA, Mandel SJ, Steward DL, et al.; American Thyroid Association Surgical Affairs Committee's Taskforce on Thyroid Cancer Nodal Surgery. The prognostic 
significance of nodal metastases from papillary thyroid carcinoma can be stratified based on the size and number of metastatic lymph nodes, as well as the presence of extranodal extension. Thyroid. 2012;22(11):1144-52.

23. UpToDate - Differentiated thyroid cancer: surgical treatment. Available from: <www.uptodate.com>. Accessed on: Set 23, 2013.

24. Rosario PW, Furtado Mde S, Mineiro Filho AF, Lacerda RX, Calsolari MR. Value of diagnostic radioiodine whole-body scanning after initial therapy in patients with differentiated thyroid cancer at intermediate and high risk for recurrence. Thyroid. 2012;22(11):1165-9.

25. Rosario PW, Mourão GF, dos Santos JB, Calsolari MR. Is empirical radioactive iodine therapy still a valid approach to patients with thyroid cancer and elevated thyroglobulin? Thyroid. 2014;24(3):533-6.

26. Rosario PW, Mineiro Filho AF, Lacerda RX, dos Santos DA, Calsolari MR. The value of diagnostic whole-body scanning and serum thyroglobulin in the presence of elevated serum thyrotropin during follow-up of anti-thyroglobulin antibody-positive patients with differentiated thyroid carcinoma who appeared to be free of disease after total thyroidectomy and radioactive iodine ablation. Thyroid. 2012;22(2):113-6.

27. Valadão MM, Rosário PW, Borges MA, Costa GB, Rezende LL, Padrão $E L$, et al. Positive predictive value of detectable stimulated tg during the first year after therapy of thyroid cancer and the value of comparison with $\mathrm{Tg}$-ablation and $\mathrm{Tg}$ measured after 24 months. Thyroid. 2006;16(11):1145-9.

28. Rosário PW, de Faria S, Bicalho L, Alves MF, Borges MA, Purisch $S$, et al. Ultrasonographic differentiation between metastatic and benign lymph nodes in patients with papillary thyroid carcinoma. J Ultrasound Med. 2005;24(10):1385-9.

29. Rosário PW, Tavares WC, Borges MA, Santos JB, Calsolari MR. UItrasonographic differentiation of cervical lymph nodes in patients with papillary thyroid carcinoma after thyroidectomy and radioiodine ablation: a prospective study. Endocr Pract. 2014;20(4):293-8.

30. DeGroot LJ, Kaplan EL, McCormick M, Straus FH. Natural history, treatment, and course of papillary thyroid carcinoma. J Clin Endocrinol Metab. 1990;71(2):414-24.

31. Albuja-Cruz MB, Thorson CM, Allan BJ, Lew JI, Rodgers SE. Number of lymph nodes removed during modified radical neck dissection for papillary thyroid cancer does not influence lateral neck recurrence. Surgery. 2012;152(6):1177-83.

32. Kim SJ, Park SY, LeeYJ, Lee EK, Kim SK, KimTH, et al. Risk factors for recurrence after therapeutic lateral neck dissection for primary papillary thyroid cancer. Ann Surg Oncol. 2014;21(6):1884-90.

33. Gulcelik MA, Ozdemir Y, Kadri Colakoglu M, Camlibel M, Alagol $H$. Prognostic factors determining survival in patients with node positive differentiated thyroid cancer: a retrospective cross-sectional study. Clin Otolaryngol. 2012;37(6):460-7.

34. Roh JL, Park Cl. Sentinel lymph node biopsy as guidance for central neck dissection in patients with papillary thyroid carcinoma. Cancer. 2008;113(7):1527-31.

35. Vergez S1, Sarini J, Percodani J, Serrano E, Caron P. Lymph node management in clinically node-negative patients with papillary thyroid carcinoma. Eur J Surg Oncol. 2010;36(8):777-82.

36. Teixeira G, Teixeira T, Gubert F, Chikota H, Tufano R. The incidence of central neck micrometastatic disease in patients with papillary thyroid cancer staged preoperatively and intraoperatively as N0. Surgery. 2011;150(6):1161-7.
37. Scherl S, Mehra S, Clain J, Dos Reis LL, Persky M, Turk A, et al. The effect of surgeon experience on the detection of metastatic lymph nodes in the central compartment and the pathologic features of clinically unapparent metastatic lymph nodes: what are we missing when we don't perform a prophylactic dissection of central compartment lymph nodes in papillary thyroid cancer? Thyroid. 2014;24(8):1282-8.

38. Lee YS, Lim YS, Lee JC, Wang SG, Kim IJ, Son SM, et al. Nodal status of central lymph nodes as a negative prognostic factor for papillary thyroid carcinoma. J Surg Oncol. 2013;107(7):777-82.

39. Lepoutre-Lussey C, Maddah D, Golmard JL, Russ G, Tissier F,Trésallet $\mathrm{C}$, et al. Post-operative neck ultrasound and risk stratification in differentiated thyroid cancer patients with initial lymph node involvement. Eur J Endocrinol. 2014;170(6):837-46.

40. Durante $\mathrm{C}$, Montesano T, Torlontano M, Attard M, Monzani F, Tumino S, et al.; PTC Study Group. Papillary thyroid cancer: time course of recurrences during postsurgery surveillance. J Clin Endocrinol Metab. 2013;98(2):636-42.

41. Vaisman A, Orlov S, Yip J, Hu C, Lim T, Dowar M, et al. Application of post-surgical stimulated thyroglobulin for radioiodine remnant ablation selection in low-risk papillary thyroid carcinoma. Head Neck. 2010;32(6):689-98.

42. Rosario PW, Xavier AC, Calsolari MR. Value of postoperative thyroglobulin and ultrasonography for the indication of ablation and ${ }^{131}$ I activity in patients with thyroid cancer and low risk of recurrence. Thyroid. 2011;21(1):49-53.

43. Nascimento C, Borget I, Al Ghuzlan A, Deandreis D, Chami L, Travagli JP, et al. Persistent disease and recurrence in differentiated thyroid cancer patients with undetectable postoperative stimulated thyroglobulin level. Endocr Relat Cancer. 2011;18(2):R29-40.

44. Rosario PW, Mineiro Filho AF, Prates BS, Silva LC, Calsolari MR. Postoperative stimulated thyroglobulin of less than $1 \mathrm{ng} / \mathrm{ml}$ as a criterion to spare low-risk patients with papillary thyroid cancer from radioactive iodine ablation. Thyroid. 2012;22(11):1140-3.

45. Ibrahimpasic T, Nixon IJ, Palmer FL, Whitcher MM, Tuttle RM, Shaha A, et al. Undetectable thyroglobulin after total thyroidectomy in patients with low- and intermediate-risk papillary thyroid cancer--is there a need for radioactive iodine therapy? Surgery. 2012;152(6):1096-105.

46. Giovanella L, Ceriani L, Suriano S, Ghelfo A, Maffioli M. Thyroglobulin measurement before rhTSH-aided 1311 ablation in detecting metastases from differentiated thyroid carcinoma. Clin Endocrinol (Oxf). 2008;69(4):659-63.

47. Pellegriti G, Scollo C, Lumera G, Regalbuto C, Vigneri R, Belfiore A. Clinical behavior and outcome of papillary thyroid cancers smaller than $1.5 \mathrm{~cm}$ in diameter: study of 299 cases. J Clin Endocrinol Metab. 2004;89(8):3713-20.

48. Giovanella L, Ceriani L, Ghelfo A, Keller F. Thyroglobulin assay 4 weeks after thyroidectomy predicts outcome in low-risk papillary thyroid carcinoma. Clin Chem Lab Med. 2005;43(8):843-7.

49. Toubeau M, Touzery C, Arveux P, Chaplain G, Vaillant G, Berriolo $A$, et al. Predictive value for disease progression of serum thyroglobulin levels measured in the postoperative period and after (131)I ablation therapy in patients with differentiated thyroid cancer. J Nucl Med. 2004;45(6):988-94.

50. Robenshtok E, Grewal RK, Fish S, Sabra M, Tuttle RM. A low postoperative nonstimulated serum thyroglobulin level does not exclude the presence of radioactive iodine avid metastatic foci in intermediate-risk differentiated thyroid cancer patients. Thyroid. 2013;23(4):436-42. 